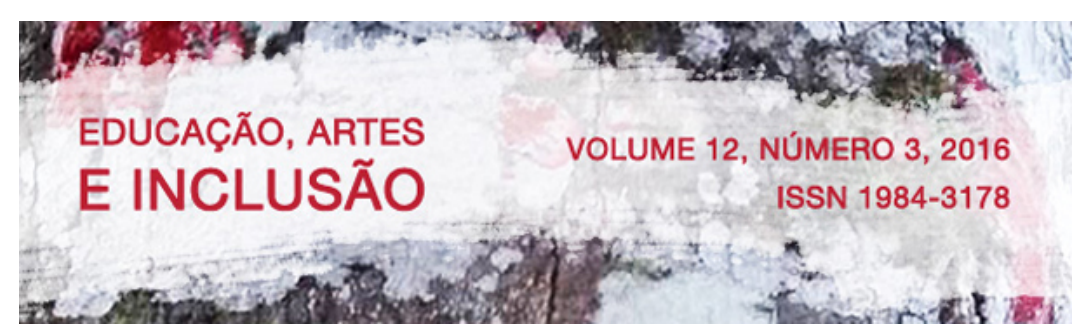

\title{
ENSINO DA ARTE E INCLUSÃO: RELATOS DE ALUNOS COM DEFICIÊNCIA VISUAL EM AULAS DE ARTES VISUAIS NO COLÉGIO PEDRO II
}

\author{
ART EDUCATION AND INCLUSION: REPORTS BY STUDENTS WITH \\ VISUAL IMPAIRMENTS IN VISUAL ARTS CLASSES AT THE COLÉGIO \\ PEDRO II
}

DOI: http://dx.doi.org/10.5965/1984317812032016033

Leila Gross - UFRJ

Monique Andries Nogueira - UFRJ

\begin{abstract}
RESUMO
Este artigo apresenta parte dos resultados da pesquisa de doutorado sobre a inclusão de alunos com deficiência visual nas aulas de artes do Colégio Pedro II, que por preconizarem não apenas o fazer artístico, mas também a história da arte e a leitura da obra, constituem conteúdo bastante sistematizado. A pesquisa se caracterizou como um estudo de caso, que busca identificar as especificidades da intermediação da imagem no Ensino da Arte para alunos com deficiência visual, incluídos nas turmas comuns. $\mathrm{O}$ estudo tem como referências para esta intermediação a descrição de obra de arte segundo Rebel (1996) e Panofsky $(1964,1991)$, e se utiliza de Franco (2010) para sua respectiva áudio-descrição. Para tanto investigou-se, através da realização de grupos focais com estes alunos, a recepção dos materiais táteis utilizados nas aulas de Artes Visuais, isto é, a compreensão das reproduções através do tato, a memória tátil e a possibilidade de fruição estética, assim como a acessibilidade aos mesmos nas suas variantes bi-, tridimensionais ou interpretações de pinturas em alto-relevo. Como resultado, os participantes demonstraram não apenas aquisição de conhecimento sobre arte, mas também revelaram experiências de fruição estética frente às reproduções das obras, além de valorizarem as próprias criações artísticas.
\end{abstract}

PALAVRAS-CHAVE: Ensino da Arte. Inclusão. Deficiência visual.

\begin{abstract}
This article presents part of the doctoral research results on the inclusion of students with visual disabilities in art classes at the Colégio Pedro II. The program content is well systematized and includes art production and also art history and art appreciation. This research is presented as a case study and aims to identify the specificities of mediating access to images in Art Education for students with visual impairments, included in ordinary classes. The references for intermediation and for artwork description are Rebel (1996) and Panofsky (1964, 1991), and Franco (2010) for audiodescription. The study used the method of focal groups with these students, to investigate the use of tactile materials in Art classes, their comprehension of reproductions through touch, their tactile memory enabling a means of aesthetic appreciation, so as to access variations in two and three dimensions or high relief interpretations or paintings. The results showed that the students not only acquired knowledge about Art, but also experienced aesthetic appreciation of reproductions of artworks, besides giving greater value to their own creations.
\end{abstract}

KEYWORDS: Art Education. Inclusion. Visual impairment. 


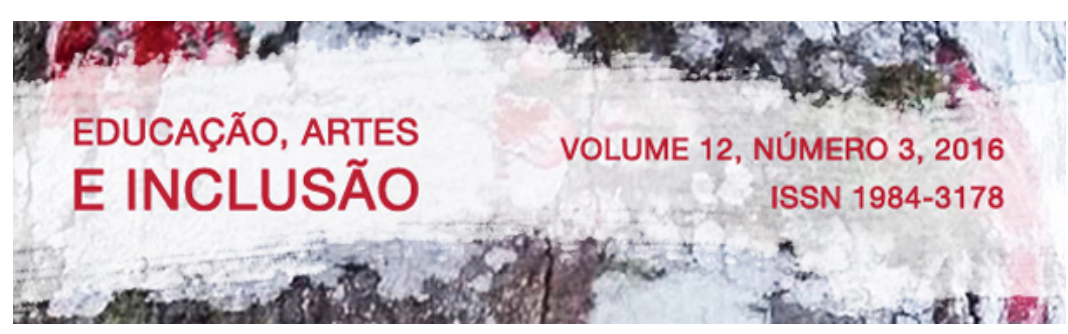

\section{INTRODUÇÃO}

Em decorrência de convênio firmado entre o Colégio Pedro II e o Instituto Benjamin Constant ${ }^{1}$, ambas instituições federais localizadas na cidade do Rio de Janeiro, alunos com deficiência visual ingressam no Colégio Pedro II, sem necessidade de concurso de admissão, para cursar o Ensino Médio. Trabalhando como professora de Artes Visuais, lecionando para alunos cegos e com baixa visão incluídos nas turmas comuns, foi observado que uma intermediação da imagem eficiente é uma das principais medidas a ser tomada pelos professores para que a inclusão deste grupo de alunos seja bem sucedida.

Entre as disciplinas curriculares que possuem grande carga imagética estão as Artes Visuais. Há necessidade de intermediar imagens através de reproduções táteis de obras de arte, aliadas à respectiva audiodescrição, técnica de acessibilidade para o cinema e teatro, utilizada também para a imagem estática. É realizada ainda a "descrição" das obras, procedimento utilizado nas aulas com alunos com e sem deficiência, para o aprofundamento da percepção dos elementos visuais e da história da arte. Assim, a descrição e a audiodescrição de imagens são trabalhadas conjuntamente, tornando o Ensino da Arte acessível para todos os alunos com e sem deficiência.

A acessibilidade às aulas de Artes Visuais fez com que um dos alunos cegos, no colégio desde o $2^{\circ}$ segmento do Ensino Fundamental, em entrevista para pesquisa intitulada “O Ensino da Arte no Colégio Pedro II" (CARDOSO JR., 2010), desse depoimento significativo sobre sua experiência com a arte:

1

O Colégio Pedro II é um dos mais tradicionais colégios brasileiros, tendo sido fundado em 1837. Equipara-se aos Institutos federais e conta atualmente com 13 mil alunos, em 14 diferentes campi. O Instituto Benjamin Constant é um centro de referência nacional para questões relativas à deficiência visual, tendo múltiplas atividades, como, reabilitação, capacitação de profissionais, produção de material especializado, impressos em braille, atendimento oftalmológico, além de pesquisa e publicações na área. Possui ainda uma escola que atende crianças com deficiência visual desde a Educação Infantil. Por não oferecer o Ensino Médio, muitos de seus alunos optam por continuarem os estudos no Colégio Pedro II, configurando uma parceria entre essas duas instituições centenárias. Disponível em: <www.ibc.gov.br>. Acesso em: 02.04.2013. 


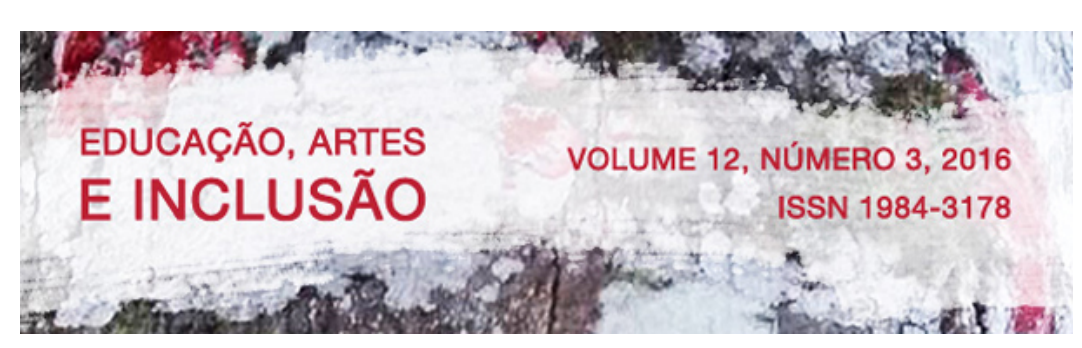

A descrição de obras de arte remonta à Antiguidade Clássica. Ao traçar seu histórico no Ocidente, Rebel (1996) se reporta à Ekphrasis, termo grego para descrição de obra de arte, concebida como exercício retórico. Seu principal representante foi Filostrato, o Antigo (ca. 190 d.C. a ca. 230 d.C.). Em seus escritos observa-se, além da pura descrição da cena pintada, a fonte de onde a cena foi tirada - a mitologia, criando no espectador o interesse pela pintura, através das histórias que vão sendo contadas:

Filostrato não só traduz, ele também substitui; parafraseia e constitui ao mesmo tempo. Ele abre, orienta, assume a direção, relata, descreve e comenta. Juntamente com as peculiaridades da pintura, ele torna "visível" a sabedoria e a força imagética de sua própria língua (REBEL, 1996, p. 19) 4.

As descrições de Filostrato tinham como objetivo o exercício da linguagem, possivelmente a pintura, a qual se refere em seus textos, era imaginária. De fato, a descrição de uma imagem amplia a capacidade de expressão verbal, ou, nas palavras de Rebel, a "força imagética da própria língua”. No exercício da descrição e interpretação das obras, os alunos, além de desenvolverem a expressão oral, tornam a percepção visual mais acurada, reparam que aquilo que haviam visto superficialmente só é melhor compreendido a partir de uma observação mais detalhada. Quando são acrescentados os contextos histórico e iconográfico à interpretação dos alunos, a imagem adquire novos sentidos. A percepção se dá, assim, em níveis de complexidade. Além disso, com a presença de alunos com deficiência visual, se estabelece um jogo entre aquele que vê a imagem e a descreve para aquele que não a vê, este último dá um retorno das lacunas do que não está sendo descrito.

Para a intermediação da História da Arte para os alunos com deficiência visual durante as aulas, foi necessária a produção de um acervo, composto de: 1. reproduções táteis bidimensionais; 2 . interpretações de pinturas em alto-relevo com modelagem em massa; 3. maquetes de pinturas (interpretações tridimensionais); 4. objetos confeccionados em cerâmica e materiais diversos e 5. cópias e réplicas de esculturas. $\mathrm{O}$ acervo exemplifica o conteúdo da disciplina do $1^{\circ}$ ano do Ensino Médio (movimento Dadaísta e Arte

Cf.o trecho original: Philostrat übersetzt also nicht nur, er ersetzt auch; er paraphrasiert und konstituiert zugleich. Er eröffnet, lenkt, nimmt Regie, berichtet, schildert und kommentiert. Zusammen mit den Besonderheiten des Gemäldes lässt er das Vorgewusste und die Bildkraft der eigenen Sprache "sehen" (REBEL, 1996, p. 19). 


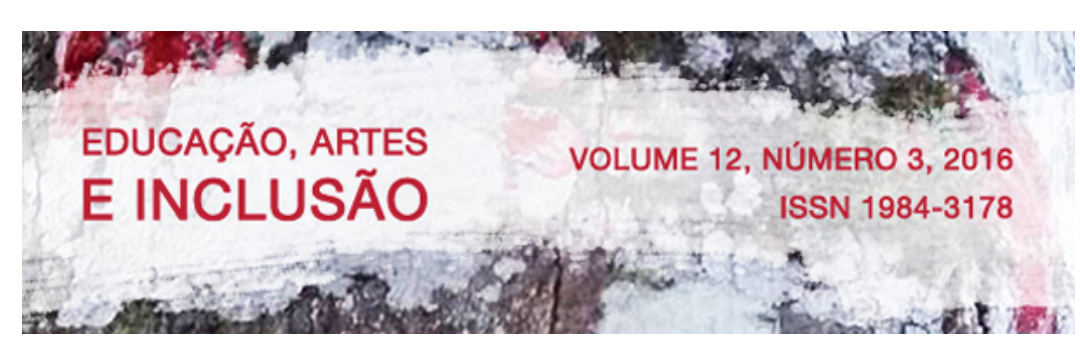

Contemporânea), assim como conceitos básicos dados no Ensino Fundamental (formas abstratas e figurativas, estilizadas e naturalistas, as mudanças na concepção de beleza no decorrer da história e em diferentes culturas e as características da arte tradicional e moderna).

A pesquisa analisou especificamente a representação bidimensional de imagens com texturização de áreas de cor, valorização dos contornos das figuras reproduzidas nos quadros, em contraposição a soluções tridimensionalizadas, como interpretações de pinturas em altorelevo e escultura.

\section{O MÉTODO}

A pesquisa foi realizada através de entrevistas semi-estruturadas com grupos focais com alunos com deficiência visual que cursaram a disciplina Artes Visuais ministrada na $1^{\mathrm{a}}$ série do Ensino Médio. Os três grupos focais foram realizados no primeiro semestre, evitando que, pela proximidade do vestibular, realizado na segunda metade do ano, os alunos não dispusessem de tempo para participar da pesquisa. O primeiro grupo focal foi realizado em 2013 contando com duas participantes e os outros dois em 2014, com quatro alunos cada. Ao todo participaram da pesquisa dez alunos, ou seja, quase a totalidade dos alunos com deficiência visual que frequentavam o NAPNE5 em 2014. As variantes consideradas foram: 1. Alunos cegos de nascença, 2. Alunos que ficaram cegos na primeira infância, 3. Alunos que cegaram recentemente, 4. Alunos com baixa visão. Neste último grupo estão apenas os alunos com visão extremamente baixa, já que a questão do acesso à imagem é mais significativa para este grupo, não considerando os alunos com baixa visão aptos à leitura em fonte 14 ou 16.

É importante ressaltar o fato de que sou professora da casa e que vários dos alunos participantes da pesquisa cursaram a disciplina comigo, o que poderia contaminar as

\footnotetext{
Núcleo de Atendimento às Pessoas com Necessidades Específicas, criado pelo Decreto 7.611/2011, através do Programa de Educação, Tecnologia e Profissionalização para Pessoas com Necessidades Educacionais Específicas (TEC NEP), que visa a inserção e o atendimento aos alunos com deficiências nos cursos de nível básico, técnico e tecnológico nas Instituições Federais de Educação (IFEs). Disponível em: $<$ http://www.ifsc.edu.br/ensino/napne $>\quad$ e $<$ http://portal.mec.gov.br/index.php?option=com_content\&view= article\&id=12779:programa-tec-nep\&catid=190\&Itemid=164>. Acesso em: 04 jul. 2014.
} 


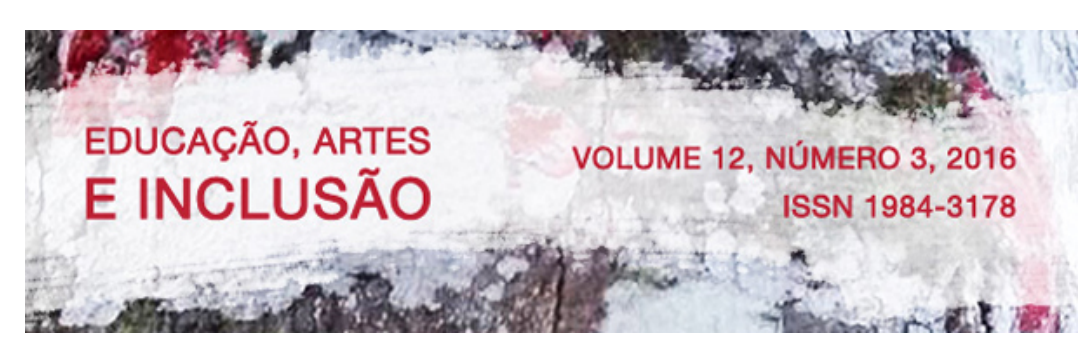

Arte se concentra na área da música, ressaltando as diferenças de abordagem das duas instituições com relação à arte na escola:

[Tatiana]: Educação Artística do Benjamin era diferente.

[Leonardo]: Era diferente do que eu aprendi aqui.

[Tatiana]: Não era Artes Visuais. Tinha apostila, falava dos...

[Leonardo]: Barroco, essas coisas...

[Tatiana]: Barroco, Classicismo...

[Wando]: Corpo. Parte corporal também.

[Entrevistadora]: Como?

[Wando]: Parte corporal também, mexer com o corpo.

[Leonardo]: É percussão corporal, que ele está dizendo.

[Entrevistadora]: Expressão?

[Leonardo]: Não. Percussão. Bater no corpo...

Entrevistadora]: Ah! Era mais música?

[Leonardo]: Era mais música, levava mais pro lado da música.

[Entrevistadora]: E mesmo Barroco e Classicismo era na música?

[Leonardo]: Não, aí falava dos autores de lá...

[Tatiana]: Mas da música...

[Entrevistadora]: Da música, né?

[Leonardo]: É, tudo levado pra música.

A nomenclatura Educação Artística, citada pelos alunos, pode englobar qualquer área das artes: Artes Visuais, Música, Teatro e Dança. No caso do IBC ela é utilizada referindo-se à Música. E mesmo a "percussão corporal" remete à Música e não à expressão corporal, como eu havia inicialmente compreendido. A tendência em evitar a disciplina subsiste não apenas na escola especial. Uma das alunas relata sua experiência com a arte na escola comum:

[Marina]: A gente estudava mais teoria, né? Eu não... tinham pinturas, eu lembro que no sexto ano a gente estudou Arte Egípcia, Arte Barroca, Arte Bizantina, um pouco da teoria, bem básico das pinturas, realmente. Não era uma... não era realmente uma matéria muito aprofundada. Eu fui ter mais aprofundamento no primeiro ano do Ensino Médio mesmo.

[Entrevistadora]: E tinha parte prática no outro colégio? Você pintava, desenhava?

[Marina]: Tinha, só pintar, desenhar, né? Era muito baseada em livro. Lia o livro, mostrava as figuras no livro, não tinha muita coisa de pintar e desenhar, não tinha muito, não.

[Entrevistadora]: Não tinha essa parte, é?

[Marina]: Tinha só um pouco. Tinha assim, uma questão na prova pra pintar, coisas assim.

[Entrevistadora]: E você fazia essa questão? 


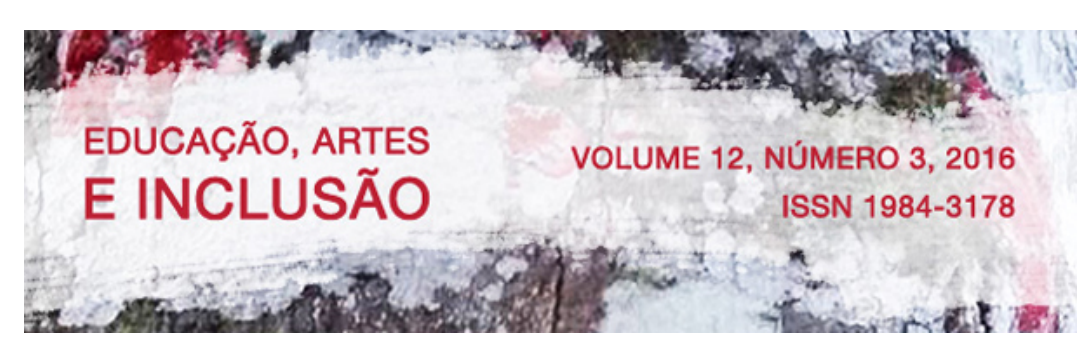

Colégio Pedro II. Todos a consideraram válida, divergindo quanto ao motivo desta importância, como se observa no seguinte diálogo:

[Entrevistadora]: O que vocês estudaram de Artes Visuais - já tem dois anos, né, que foi na primeira série - foi importante ter estudado Artes Visuais aqui no Pedro II?

[Tatiana]: Acho que foi legal pra...

[Camila]: Foi.

[Entrevistadora]: Por quê?

[Camila]: Porque vestibular não perdoa, né?

[Entrevistadora]: Você acha que cai no vestibular?

[Camila]: Ah, cai...

[Entrevistadora]: Vocês já viram o ENEM, né?

[Camila]: Já.

[Entrevistadora]: E você, Tatiana, ia falar alguma coisa?

[Tatiana]: Ah, eu acho que tudo tem a sua importância. Achei legal a experiência pra ver como que a turma tinha aula de Artes Visuais. A gente teve alguns materiais táteis pra entender. Foi bem legal a experiência.

[Wando]: Diga-se de passagem que foram bons, bem legal.

[Entrevistadora]: O quê?

[Wando]: Diga-se de passagem que foram bons também os materiais.

No primeiro trecho sublinhado observa-se a preocupação com o aspecto informativo, que aparece na fala da aluna Camila, citando o vestibular como fator de validade para o Ensino da Arte. O tema da exclusão das aulas de artes é, de certa forma, abordado por Tatiana. A frase em destaque revela uma possível curiosidade despertada por uma matéria de teor visual, que não havia sido oportunizada no Ensino Fundamental. O fato de não poder participar de determinada disciplina, pode provocar uma cisão na turma, formada por alunos que enxergam e para os quais a escola oferece todos os conteúdos, e os alunos excluídos de determinadas disciplinas por não enxergarem.

Ao se referir à importância do Ensino da Arte, Marina também cita o vestibular, mas não o coloca em primeiro lugar:

[Marina]: Foi, foi muito importante! Artes Visuais... eu tive um pouco disso no ENEM e é principalmente pra vida. É muito legal você ouvir o nome de um pintor e saber o que ele fez, qual a importância dele, no dia a dia mesmo, ah, eu sei que ele fez isso, eu sei que ele fez aquilo, já vi uma pintura dele assim e tal. É legal, muito legal. 


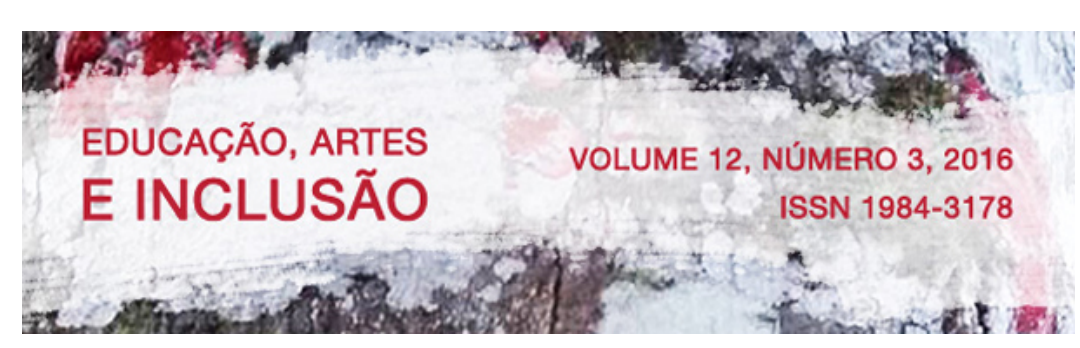

Marina aborda uma questão central nesta pesquisa: o acesso a bens culturais, a informações advindas destes, que promovem sua inserção em determinado assunto, do qual estaria excluída, caso não tivesse oportunidade de aprofundamento na área. Outra aluna também se refere a uma ampliação de seu universo cultural, quando chama atenção para a interdisciplinaridade de Artes com Literatura:

[Taís]: (...) É importante para o conhecimento e também porque a Literatura também envolve alguma coisa de Artes. Então, estudando Artes a gente já tem uma base, sentindo, né, os materiais, a gente pode ter uma base pra entender melhor Literatura que nós estudamos. Principalmente o terceiro ano pega bastante a parte de Artes que estudamos aqui.

Desta forma, Taís percebe que "sentindo" os materiais táteis pode ter uma noção sobre as Artes Visuais, potencializando interfaces com outras áreas do conhecimento.

\section{MEMÓRIA TÁTIL E APRECIAÇÃO ESTÉTICA: OBSERVAÇÕES DOS ALUNOS SOBRE AS REPRODUÇÕES TÁTEIS DE OBRAS DE ARTE}

Em vários momentos dos três Grupos Focais, alguns alunos, ao dissertarem sobre arte, foram bastante específicos em suas falas, revelando uma excelente capacidade de memória envolvendo os temas, artistas e movimentos estudados. A aquisição de vocabulário específico da área fica patente no trecho a seguir:

[Entrevistadora]: Foi importante ter estudado Artes Visuais? Por quê? [Maria]: Eu acho que foi legal pra conhecer mesmo, não imaginava que era daquele jeito, tipo, as evoluções. Como é que foi... (como é que é a palavra?) foi se desenvolvendo... tipo, desde o naturalismo, como é que foi indo, como é que foi mudando, se transformando, as artes, as pessoas... Bem bacana.

Maria cita o naturalismo na arte e suas transformações, ou seja, o processo de estilização. Outros exemplos do conhecimento dos alunos sobre o tema foram coletados nos demais grupos focais, como é possível conferir no diálogo abaixo:

[Entrevistadora]: Vocês se lembram de alguma obra de arte?

[Pâmela]: Eu lembro daquele vaso. Aquele vaso (risos).

[Stefani]: O mictório, é do Marcel... é... "A Fonte". 


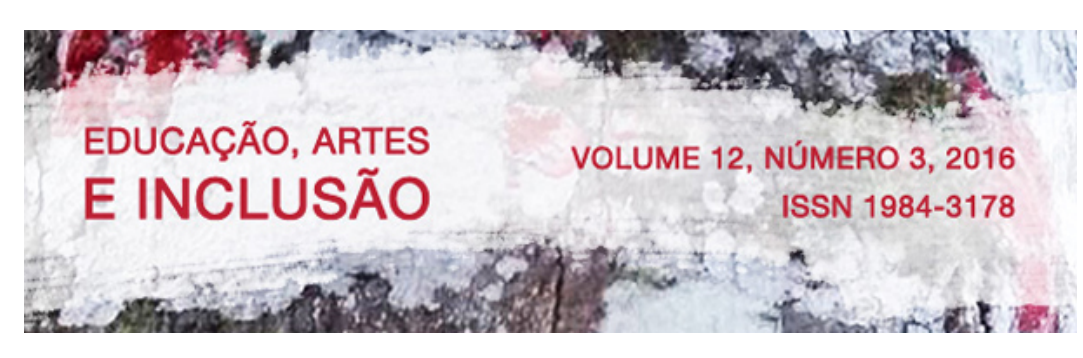

Marcel Duchamp, Picasso, Van Gogh e Monet são os artistas elencados, estes últimos, associados à exposição "Impressionismo: Paris e a Modernidade", visitada em 2012 no Centro Cultural Banco do Brasil. Quanto a expressões contemporâneas de arte, os alunos se lembraram de várias obras:

[Entrevistadora]: (...) Vocês lembram da Arte Contemporânea, alguma expressão artística contemporânea?

[Stefani]: "Panela de Pressão"?

[Entrevistadora]: Ah, aquilo ali era.

[Rogério]: Ah, eu não lembro não.

[Stefani]: Da época da Ditadura.

[Pâmela]: Eu acho que eu não conheço essa "Panela de Pressão" não, hein!

[Stefani]: Não, gente? Minha memória tá melhor que a de vocês (risos). É, deixa eu ver... uma de Arte Contemporânea... Ai, tinha tanto, tinha.. Ah, e as vídeo instalações eram o quê?

[Entrevistadora]: Isso!

[Stefani]: Vídeo instalação.

[Pâmela]: Isso eu lembro.

[Rogério]: Ah.

[Pâmela]: A da "Marilyn", era isso?

[Entrevistadora]: Isso!

[Pâmela]: Ah, legal.

[Rogério]: A gente até ia fazer uma no fim do ano, no percurso, mas não deu tempo, né?

[Entrevistadora]: Foi.

[Stefani]: Eu achava legal aquelas figuras, por exemplo, tinha aquela do sorvete, o sorvete gigante assim! E o legal é que mexe muito com a nossa imaginação. É muito legal. Tinha mais o quê? A vídeo instalação, instalação... tinha aquela como se fosse uma torre cheia de rádio de comunicação e cada um dizendo uma língua... Tinha... ah, não sei!

São citados objetos como a "Panela de Pressão", de Cláudio Tozzi, realizada durante a ditadura militar no Brasil, a instalação "Babel” de Cildo Meireles, mencionada por Stefani, e obras Pop, como a serigrafia de Marilyn Monroe ou o grande sorvete de Claes Oldenburg, intitulado "Cone Caiu".

É importante ressaltar que todas estas perguntas foram feitas sem a presença dos materiais táteis, o que redimensiona as respostas dadas. Não há dúvida que o conteúdo da disciplina é compreendido pelos alunos com deficiência visual, que, além disso, conferem juízo estético às obras estudadas e aos próprios materiais. Os depoimentos a seguir se referem à interpretação tátil da pintura "Caipira Picando Fumo" de Almeida Jr., expressando critérios de apreciação estética: 


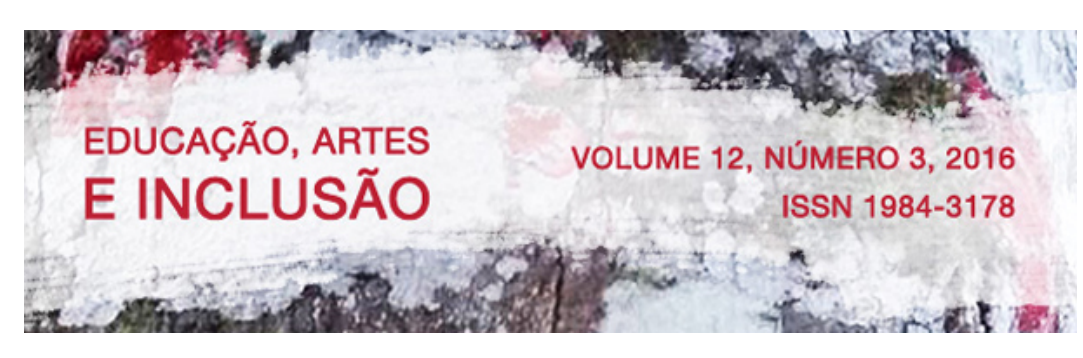

Marina cita releituras realizadas por ela destes materiais durante as aulas de artes. Provavelmente a experiência com a obra adquire maior proximidade através da interpretação, não apenas verbal, mas plástica da mesma, tornando-a mais significativa. A aluna diz que o “Abaporu" ficou gravado em sua mente, pelo fato de ser esta "figura tão diferente", de serem suas formas surpreendentes. Se contrapondo à constância da percepção rotineira, a arte promove a experiência do inusitado, do insólito, do estranhamento frente ao desconhecido. Da maneira como Marina se refere às releituras realizadas das obras em questão e sua relação com as formas inéditas do "Abaporu", conclui-se que tais reações ocorrem de forma semelhante às pessoas que enxergam. Ou seja, ter acesso às obras citadas através do tato e expressá-las tridimensionalmente, tem equivalência com interagir com as referidas imagens através da visão, estando o aluno cego submetido aos mesmos fenômenos que aquele que enxerga.

Em um dos grupos focais surgiu o seguinte diálogo durante a observação das reproduções táteis:

[Entrevistadora]: (...) Vocês gostam de alguma dessas? Ah, isso é bonito, isso é interessante... Qual que vocês gostam mais? Ou é indiferente?

[Taís]: Não, não é indiferente.

[Maria]: Não, não é indiferente não. Eu gosto... dessas que eu vi, eu gostei da Caça.

[Entrevistadora]: Ãham, a Diana.

[Maria]: Deixa eu pensar.

[Taís]: Essa daqui...

[Entrevistadora]: Essa é uma estrutura africana.

[Taís]: Qual?

[Maria]: A da Barbie.

[Taís]: Ah, da Barbie (risos) eu falei que era magrinha (risos).

[Maria]: Ah, não sei, mas não é indiferente, entendeu? Eu acho bacana, eu gosto.

[Taís]: E a dos quadros também, que tá em cartão, em alto-relevo também.

[Maria]: Ãham! Eu gosto também.

[Entrevistadora]: É da Pop Art, lembra?

[Taís]: Ah, é, Pop Art!

[Maria]: É sério, poderia ficar aqui vendo... Veria, veria, veria. Sério, eu achei legal, essa...

[Entrevistadora]: Você gosta também?

[Taís]: Eu gosto.

As alunas fazem associação de uma escultura africana, de formas extremamente afinadas, com a boneca Barbie, buscando referências imagéticas para as peças mostradas. 


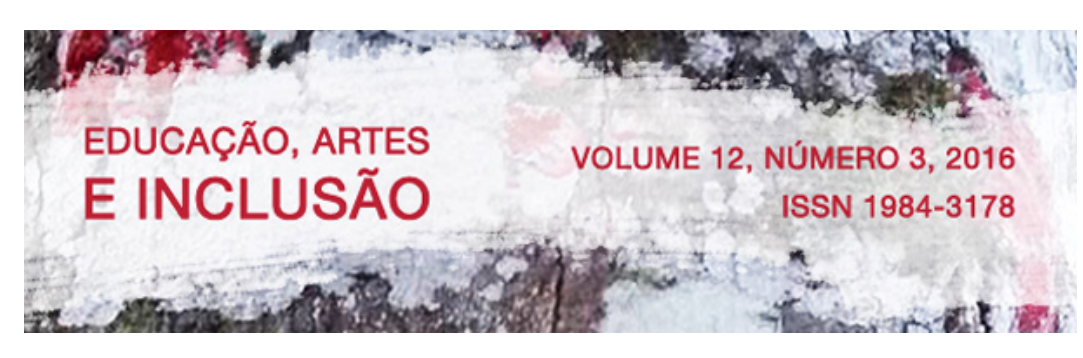

Ambas valorizam esteticamente não só materiais tridimensionais, mas também os bidimensionais, como a reprodução de Marilyn, mais difícil de ser compreendida sem audiodescrição. Ou seja, a facilidade de compreensão não interfere no juízo de gosto.

Vale ressaltar o quanto a observação das reproduções táteis demonstra ser prazerosa. Em diversos momentos durante a mostragem dos materiais táteis, os alunos se divertiam, comentando o que percebiam. No terceiro grupo focal, Pâmela, que tem baixa visão, fazia a audiodescrição, enquanto Stefani percebia tatilmente a interpretação em alto-relevo da pintura "Abaporu”, de Tarsila do Amaral:

[Stefani]: A Pâmela é uma ótima descritora (risos). Ah, nossa!

[Rogério]: Que maneiro, que maneiro.

[Stefani]: Minha filha, você é deformada. O pé é grandão. Isso aqui é o quê? Isso é um olho?

[Entrevistadora]: É o sol.

[Stefani]: Ah! (risos)

[Pâmela]: A cabeça é pequenininha pra cá. Olha a cabeça.

[Stefani]: Ah, desculpa. Ih, saiu.

[Entrevistadora]: Não, é assim mesmo.

[Stefani]: Gente, cadê a cabeça?

[Pâmela]: Tá escondidinha.

[Entrevistadora]: Tá aqui.

[Stefani]: Ah, pensei que ela tinha nascido assim. Isso é um sol. E isso aqui?

[Entrevistadora]: É um cacto, uma planta.

Nota-se pelas falas dos alunos, que o observar e comentar sobre as obras através dos materiais táteis, se configura numa experiência lúdica. Alguns depoimentos destacam a inclusão destes materiais na aula de artes e a reação da turma frente a eles:

[Rogério]: Bom, eu achei legal até pela diversidade dos materiais táteis que aqui possui. Então eu achei muito legal porque a professora de artes também se preocupa muito com o material, se os deficientes visuais estão conseguindo acompanhar e tal e eu achei legal justamente por conseguir incluir a gente. A mesma coisa que a turma está vendo na apostila é a mesma coisa que tá sendo mostrada pra gente em desenho tátil. Então, por mim eu achei bem legal.

[Pâmela]: Eu também gostei. As mesmas coisas que a turma tinha, a gente também tinha. Inclusive, acho que a turma gostava mais do nosso do que do deles. Eles ficavam: "Ah, deixa eu ver, deixa eu pegar. Olha, aqui tem uma curvinha!" Porque tem coisas que na imagem você não repara e ele na sua mão você vai reparar automaticamente, logo que você colocar a mão você vai reparar. E eu acho que é isso, o material que tinha disponibilizado era bom, a professora sabia como trabalhar com ele, com esse material e sempre com aquela coisa: "Você tá entendendo? Você não 


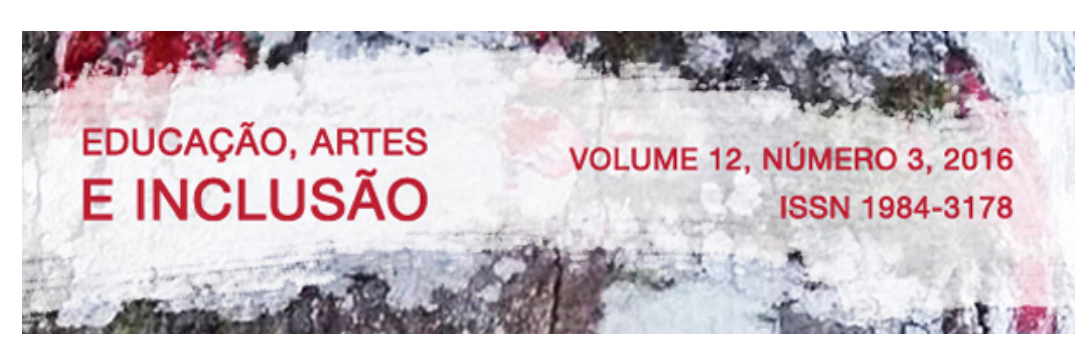

[Entrevistadora]: Isso, isso!

[Leonardo]: Eu não sei qual era o bicho. Era um carneiro? Eu não lembro. Qual era o bicho?

[Entrevistadora]: Era um cervo, não era?

[Leonardo]: Era um cervo, isso.

[Entrevistadora]: Muito bem.

[Leonardo]: Esse é legal. Eu lembro, vi duas vezes (risos).

[Wando]: (inaudível).

[Leonardo]: Ele falou o nome baixinho (risos)... Diana.

[Tatiana]: Eu lembro... Acho que foi uma das primeiras.

[Leonardo]: É foi uma das primeiras esculturas que a gente viu.

[Tatiana]: É. Se não foi a primeira.

[Entrevistadora]: Exatamente.

[Camila]: Foi a primeira, eu acho. Diana.

A escultura grega suscita duas demandas absolutamente interligadas: compreender as formas representadas e relacioná-las à sua iconografia. Como acontecera com Maria, a partir da observação da reprodução, os alunos aos poucos se lembraram dos seus significados até chegar ao nome da personagem representada.

Com relação ao reconhecimento das formas, o material tridimensional oferece maior facilidade para a pessoa cega. Em contraposição, há maior dificuldade em reconhecer materiais bidimensionais, como se evidencia no diálogo abaixo, durante a observação da serigrafia de Marilyn Monroe. Pâmela, que tem baixa visão, ajuda Stefani, descrevendo e guiando sua mão sobre a prancha:

[Stefani]: Esse aqui é o Andy Warhol...

[Entrevistadora]: Esse é o Andy Warhol, isso mesmo!

[Stefani]: Esse caiu na minha prova. Isso aqui... isso é uma boca?

[Pâmela]: É. Calma aí, depende. O que estava nessa mão aqui é uma boca, na outra mão, não é não.

[Stefani]: É (risos) E, mas cadê? Aqui...

[Entrevistadora]: A boca é aqui, olha.

[Pâmela]: Aqui é o nariz...

[Stefani]: Gente, eu estou cega da mão. Cadê?

[Pâmela]: Pô, aí é triste, né, do olho, da mão...

[Stefani]: (risos).

[Pâmela]: Pelo menos escuta.

[Stefani]: Isso aqui é um olho? Não... Não! Isso aqui... Ai, que mico, gente! Isso é o quê?

[Entrevistadora]: É o cabelo.

[Stefani]: Cabelo, é?

[Entrevistadora]: Os olhos estão aqui.

[Pâmela]: Ela é loira mesmo?

[Entrevistadora]: É. 


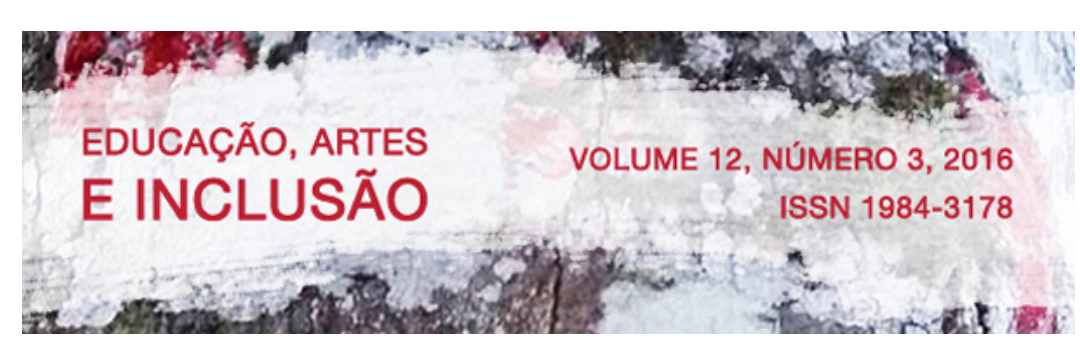

Observa-se que Stefani fica bastante perdida ao manusear a prancha. Este material tátil foi realizado em papel cartão, com contornos realçados com tinta relevo, mantendo as cores e o espaço chapado da obra original.

Em contato com a mesma reprodução, os alunos do segundo grupo focal não tiveram dificuldades em sua compreensão:

[Leonardo]: Ah, Monalisa! Oh, Monalisa o quê! Marilyn Monroe! Legal. Eu lembro dela.

[Entrevistadora]: E essa reprodução bidimensional, é mais difícil ou é mais fácil?

[Wando]: Qual, esse aqui?

[Camila]: Difícil não é não, mas tridimensional é melhor.

[Leonardo]: Consegue ver os detalhes dos olhos?

[Wando]: Consigo.

[Leonardo]: Então. Onde é que é a boca dela? Aí, ó!

[Entrevistadora]: Dá pra perceber aonde que é?

[Wando]: Com o olho dá.

[Leonardo]: Ele tá olhando! Esperto. (risos)

[Wando]: Olhando mais ou menos... esse aqui é mais... sei lá.

[Entrevistadora]: Você consegue perceber enxergando?

[Wando]: Ãham.

[Leonardo]: Mas eu acho, professora, que ele é mais visível do que tátil, esse daí.

[Entrevistadora]: Por causa das cores, né?

[Leonardo]: Mais visual, quer dizer.

Leonardo tem perda progressiva da visão e consegue enxergar vultos. Wando é usuário de braille, mas tem resquícios de visão e revela que o material tátil, bastante colorido, é identificado com os olhos. Leonardo conclui que a reprodução de "Marilyn", "é mais visível do que tátil". De fato, as formas são coloridas com cores vivas e contrastantes, típicas do movimento Pop Art.

A confecção deste material foi feita a partir de fotocópias da obra em questão. Um procedimento bastante simples, tendo como base uma reprodução colorida de toda a pintura como fundo, onde foi colada uma outra fotocópia da figura principal, no caso, o rosto de Marilyn, recortado e colado sobre papel cartão, de forma que sua silhueta fica mais alta que o fundo. Os contornos do rosto, cabelo, assim como os olhos e boca foram ressaltados com tinta relevo. Assim, a prancha não é totalmente plana, suas formas apresentam diferenças de espessura. 


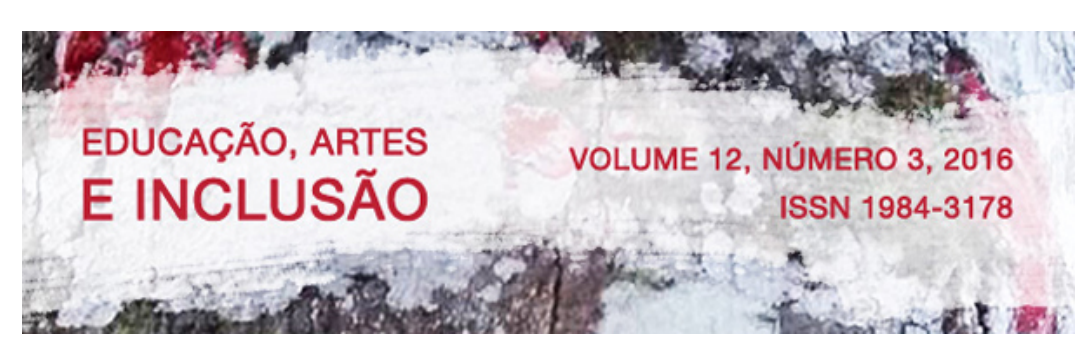

(...)

[Entrevistadora]: O Abaporu você acha que é mais difícil de entender... [Marina]: Sim.

[Entrevistadora]: Mas o que você acha mais interessante? Ele é interessante? É válido fazer reproduções também que sejam em altorelevo?

[Marina]: Assim, eu acho que tem uma contradição aí, porque o Abaporu dessa forma, meio bidimensional, meio em alto-relevo, ele mostra exatamente como os outros veem, entendeu? Então eu vou ter a mesma representação. Mas eu acho que se tivesse, por exemplo, o homem sentado, o Caipira aqui sentado, se fosse bidimensional eu acho que não ficaria tão, vamos dizer, entendível, tão legível quanto ele é agora tridimensional.

No trecho sublinhado nota-se que Marina chama atenção para a fidedignidade do material tátil com o original. A reprodução de uma pintura deve mostrar "exatamente como os outros veem", ou seja, manter seu caráter bidimensional. E aí se observa a contradição mencionada pela aluna: para a pessoa cega, uma imagem representada numa prancha é mais difícil de ser identificada do que a sua maquete. Isso ocorre justamente porque a pessoa que não enxerga não tem o hábito de se deparar com representações no espaço plano, tão corriqueiras para o indivíduo que vê. Porém, entrar em contato com uma pintura é se arriscar na dimensão plana e nos seus artifícios para representar ou negar a espacialidade, construindo ambientes desconhecidos para a pessoa com cegueira congênita ou adquirida na primeira infância.

Marina, ao observar a prancha bidimensional representando "Marilyn", comenta:

[Marina]: Eu sei que é uma pessoa, né? Um rosto.

[Entrevistadora]: Você já falou nela hoje.

[Marina]: É a Marilyn Monroe?

[Entrevistadora]: É!

[Marina]: Ah é, ela mesma.

[Entrevistadora]: Essa daí é bidimensional, ela não tá em alto-relevo.

[Marina]: Essa eu acho que não precisa ser, por exemplo, tridimensional porque ela só tem a imagem do rosto. Por exemplo, uma coisa que eu acho que fica melhor tridimensional é quando você tem uma imagem assim: uma mão passando na frente do corpo, entendeu?

[Entrevistadora]: Ãham...

[Marina]: Essas coisas ficam melhor tridimensional. Agora quando é assim, uma figura, uma imagem, vamos dizer, plana... 


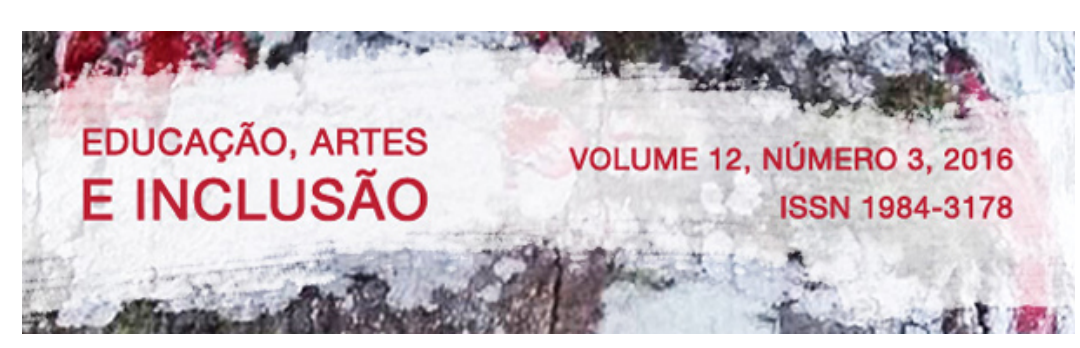

MATTOSO, V. A. Ora, Direis, Ouvir Imagens? Um olhar sobre o potencial informativo da audiodescrição aplicada a obras de artes visuais bidimensionais como representação sonora da informação em arte para pessoas com deficiência visual. Dissertação (Mestrado em Ciência da Informação) - Universidade Federal do Rio de Janeiro - UFRJ, 2012.

NOGUEIRA, M. A. Arte e Experiência Estética: o assombro aproximando crianças e adultos. In: ZANOLLA, S. R. S. Arte, Estética e Formação Humana: possibilidades e críticas. Campinas: Alínea, 2013.

OLIVEIRA-JÚNIOR, J. N. Ouvindo Imagens: a audiodescrição de obras de Aldemir Martins. Dissertação (Mestrado em Linguística Aplicada) - Programa de Pós-Graduação em Linguística Aplicada, Universidade Estadual do Ceará, 2011. Disponível em: $<$ http://www.uece.br/posla/dmdocuments/JuarezNunesdeOliveiraJ\% C3\%BAnior $>$ Acesso em: 20.10.2014.

PANOFSKY, E. Significado nas Artes Visuais. São Paulo: Perspectiva, 1991.

Zum Problem der Beschreibung und Inhaltsdeutung von Werken der bildenden

Kunst. In: Panofsky, E. Aufsätze zu Grundfragen der Kunstwissenschaft. Berlin: Oberer und Verheyen, 1964.

REBEL, E. Sehen und Sagen: Das Öffnen der Augen beim Beschreiben der Kunst. Ostfildern: Ed. Tertium, 1996.

REILY, L. H. Músicos Cegos ou Cegos Músicos: representações de compensação sensorial na história da arte. Cadernos Cedes, Campinas, vol. 28, n. 75, p. 245-266, maio/ago. 2008. Disponível em: <http://www.cedes.unicamp.br>. Acesso em: 28.10.2014.

WÖLFLIN, H. Conceitos Fundamentais da História da Arte. São Paulo: Martins Fontes, 1989a. . Renascença e Barroco. São Paulo: Perspectiva. 1989b.

\section{SITES CONSULTADOS}

$<w w w . i b c . g o v . b r>$

$<$ www.ifsc.edu.br/ensino/napne $>$

$<$ portal.mec.gov.br $>$

Recebido em 31 de maio de 2016 Aprovado em 6 de setembro de 2016 